\title{
Efeito de aditivo químico e inoculantes microbianos na fermentação e no controle da produção de álcool em silagens de cana-de-açúcar
}

\author{
Daniel de Paula Sousa ${ }^{1}$, Wilson Roberto Soares Mattos ${ }^{2}$, Luiz Gustavo Nussio ${ }^{2}$, Lucas José \\ Mari $^{1}$, José Leonardo Ribeiro ${ }^{1}$, Matteus Castilho Santos ${ }^{1}$
}

1 Programa de Pós-graduação em Zootecnia - ESALQ/USP.
2 Departamento de Zootecnia da Escola Superior de Agricultura "Luiz de Queiroz" - ESALQ/USP.

RESUMO - Avaliou-se a eficácia de aditivo químico e inoculantes microbianos nas alterações fermentativas que inibem a produção de etanol e diminuem as perdas de matéria seca em silagens de cana-de-açúcar. A ensilagem foi realizada em baldes plásticos de 20 litros (minissilos) adaptados com válvulas tipo Bunsen para eliminação dos gases e dispositivo para coleta de efluentes. Utilizou-se uréia (1\% na matéria verde) como aditivo e os inoculantes microbianos Lalsil cana ${ }^{\circledR}$ contendo a bactéria heterolática Lactobacillus buchneri (cepa NCIMB 40788) na razão de 3,65 × $10^{5}$ ufc/g massa verde (MV) e um inoculante não comercial contendo a combinação de bactérias homo e heteroláticas Pedioccocus pentosassus e Lactobacillus buchneri $\left(1 \times 10^{6} \mathrm{ufc} / \mathrm{g}\right.$ de massa verde). As amostragens foram realizadas após 110 dias de fermentação. A utilização de uréia e principalmente do aditivo Lactobacillus buchneri + Pediococcus foi eficaz em diminuir a produção de etanol (1,30 e $2,75 \%$ vs $8,27 \%$ na silagem controle), as perdas de matéria seca (47 e $60 \%$ ) e o consumo de carboidratos solúveis (22 e 56\%) e em aumentar a digestibilidade in vitro da matéria seca $(14,7$ e $12,4 \%)$ quando comparados à silagem controle, respectivamente. Apesar dos altos teores de ácido acético em todas as silagens, principalmente nas silagens acrescidas da combinação de bactérias homo e heteroláticas, não foram verificados efeitos dos inoculantes sobre a população de leveduras. Os valores de pH e ácido lático da silagem com uréia foram maiores que os obtidos na silagem controle. As silagens com L. buchneri apresentaram neste estudo maior produção de etanol (11,53\% vs $8,27 \%$, silagem controle), o que refletiu em perdas significativas e baixa recuperação de matéria seca, além de baixa digestibilidade pela perda de carboidratos solúveis e pelo acúmulo de FDN, que foram similares aos das silagens sem aditivo.

Palavras-chave: Lactobacillus buchneri, leveduras, Pedioccocus pentosassus, uréia

\section{Chemical additive and microbial inoculants effects on the fermentation and on the control of the alcohol production in sugarcane silages}

\footnotetext{
ABSTRACT - The objective of this study was to evaluate chemical additive and microbial inoculants effectiveness on fermentative changes that lead to the inhibition of the ethanol production and reduction of dry matter losses in sugarcane silages. Silos were made in 20 liter plastic buckets provided with a Bunsen type valve that allows gas to escape and a device to collect effluents. The applied additives were urea (1\% of fresh forage); microbial additive Lalsil cana ${ }^{\circledR}$, that has heterolactic bacteria Lactobacillus buchneri (NCIMB 40788), $3.65 \times 10^{5} \mathrm{CFU} \mathrm{g}^{-1}$ of fresh forage, and a noncommercial additive with homolactic bacteria Pedioccocus pentosassus and Lactobacillus buchneri $\left(1 \times 10^{6} \mathrm{CFU} \mathrm{g}^{-1} \mathrm{FM}\right)$ supplied by Lallemand Inc. (Montreal, Quebec). Sampling occurred after 110 days of fermentation. Urea and mainly the additive Lactobacillus buchneri and Pediococcus were efficient on the reduction of ethanol production (1.30 and $2.75 \%$ versus $8.27 \%$ in the control treatment), on the reduction of dry matter losses (47 and $60 \%$ ) and soluble carbohydrates (22 and 56\%), and increase in vitro dry matter digestibility (14,7 and 12,3\%) when compared to the control silages, respectively. Despite the high values of acetic acid in all silages, mainly in silages inoculated with homo and heterolactic bacteria, it was not verified effects on yeast population. The silage with urea had greater values of $\mathrm{pH}$ and lactic acid compared to control silage. Silages with L. buchneri had, in this experiment, the largest ethanol production (11.53\% vs $8.27 \%$ from control silage), resulting in greater losses and lower dry matter recovery. In addition, these silages also showed lower digestibility because of soluble carbohydrates losses and NDF accumulation, similar to the silages without additive.
}

Key Words: Lactobacillus buchneri, Pedioccocus pentosassus, urea, yeasts 


\section{Introdução}

O alto teor de carboidratos solúveis (CS) e a grande população de leveduras epífitas fazem com que silagens de cana-de-açúcar tenham intensa fermentação alcoólica, convertendo esses CS a etanol, $\mathrm{CO}_{2}$ e água (McDonald et al., 1991). Assim, podem ocorrer perdas excessivas de matéria seca (MS), redução nos teores de CS e em seu valor nutritivo na ensilagem, além de diminuição no desempenho animal (Alli et al., 1982).

Teores de etanol na ordem de 7,8 a 17,5\% na MS têm sido relatados para a cana-de-açúcar ensilada sem o uso de aditivos (Kung Jr. \& Stanley, 1982; Andrade et al., 2001; Pedroso, 2003; Freitas et al., 2006). No entanto, Pedroso (2003) observaram diminuição de aproximadamente $50 \%$ nas perdas de MS nas silagens adicionadas de uréia em relação às silagens sem aditivos, e Andrade et al. (2001), do mesmo modo, obtiveram com a adição de uréia silagens de cana-de-açúcar com 4,14\% de etanol na MS.

Outra forma avaliada no controle da fermentação alcoólica é o uso de aditivos microbianos. Inoculantes contendo bactérias homoláticas promovem maior eficiência na produção de ácido lático, maior rapidez na acidificação e menor pH final, além de redução na taxa de degradação protéica destas silagens (Weinberg \& Muck, 1996). Como leveduras podem sobreviver em $\mathrm{pH}$ próximos ou inferiores a 2 (McDonald et al., 1991), a maior produção de ácido lático nas silagens aditivadas não foi eficiente em controlar as leveduras em silagens de cana (Pedroso, 2003; Freitas et al., 2006).

Por outro lado, têm-se demonstrado aumento da estabilidade aeróbia e melhoria na fermentação em silagens de cana-de-açúcar aditivadas com a bactéria heterolática L. buchneri (Kung Jr. \& Ranjit 2001; Pedroso 2003). O L. buchneri tem uma via metabólica de degradação anaeróbia do ácido lático, em que um mole de ácido lático é convertido em meio mol de ácido acético, meio mol de 1,2propanodiol e traços de etanol (Oude Elferink et al., 2001). Os maiores teores de ácido acético têm efeitos positivos sobre a inibição de leveduras e o controle da fermentação alcoólica (Moon, 1983), no entanto, os mecanismos ainda não são totalmente claros.

Este trabalho foi realizado com o objetivo de avaliar o efeito de aditivo microbiano heterolático (Lactobacillus buchneri) em combinação ou não com bactéria homolática (Pediococcus pentosaceus) e o aditivo químico uréia sobre a composição química, as perdas associadas à fermentação e o desenvolvimento da microflora epifítica em silagens de cana-açúcar.

\section{Material e Métodos}

O corte e a ensilagem da cana-de-açúcar variedade RB72-454 com 12 meses de crescimento foram realizados no dia 3 de novembro de 2004. O valor do grau $\mid$ Brix $^{\circledR}$ da forrageira foi determinado em refratômetro de campo (marca Tokyo ${ }^{\circledR}$, modelo 032) e apresentou valor médio de $23,4^{\circ}$. A cana foi colhida manualmente e picada, sem a retirada da palha, em máquina estacionária regulada para corte com tamanho de partícula médio de $10 \mathrm{~mm}$.

Para a produção dos silos experimentais, foram utilizados baldes de plástico de 20 litros (minissilos), com tampas próprias para vedação e adaptadas com válvulas tipo Bunsen, para que fosse possível o escape de gases e a avaliação das perdas gasosas durante o tempo de estocagem. No fundo de cada balde, foram colocados $2 \mathrm{~kg}$ de areia seca e uma tela fina de plástico com a finalidade de serem avaliados quantitativamente os efluentes.

Foram determinados o peso da forragem em cada balde com o objetivo de se atingir a densidade de $550 \mathrm{~kg} / \mathrm{m}^{3}$. Camadas sucessivas com $10 \mathrm{~cm}$ de espessura foram compactadas até o peso final do balde atingir aproximadamente $12 \mathrm{~kg}$ de forragem. Após o enchimento, os minissilos foram fechados e vedados com fita adesiva para impedimento da entrada de ar. Os silos foram, então, pesados e armazenados em local coberto.

Os tratamentos consistiram de um aditivo químico e de dois aditivos microbianos. O aditivo químico testado foi uréia na forma de fertilizante granulado contendo $45 \%$ de nitrogênio (N) na concentração de 1\% na matéria verde. Os inoculantes microbianos utilizados foram: Lalsil cana ${ }^{\circledR}$, contendo a bactéria heterolática Lactobacillus buchneri (cepa NCIMB 40788, Lallemand Inc. Montreal, Quebec) na razão de 3,65 × $10^{5} \mathrm{ufc} / \mathrm{g}$ massa verde (MV), e um inoculante não comercial contendo a combinação de bactérias Pedioccocus pentosassus, homolática e Lactobacillus buchneri, heterolática $\left(1 \times 10^{6} \mathrm{ufc/g} \mathrm{MV}\right)$, fornecidos pela Lallemand Inc. (Montreal, Quebec)

Os aditivos químicos e microbianos foram aplicados à cana-de-açúcar picada antes do enchimento dos baldes na forma de soluções aquosas utilizando-se pulverizadores manuais de 5 litros (Brudden ${ }^{\circledR}$, Brudden Equipamentos Ltda), buscando-se distribuição uniforme dos produtos na massa a ser ensilada. Todos os aditivos foram aplicados na razão de 25 litros de solução por tonelada de forragem.

Os baldes foram pesados antes da ensilagem com a tampa, a areia e a tela plástica para que fosse possível o cálculo do peso líquido de forragem contida em cada silo experimental e, posteriormente, das perdas por gases e efluentes. 
Os minissilos foram pesados e as silagens foram amostradas aos 110 dias após o enchimento dos silos. Procedeu-se à pesagem inicial, à retirada da forragem e à pesagem do balde junto à tampa, à areia e à tela de plástico. A diferença de peso entre o conjunto vazio antes do enchimento e após a abertura permitiu estimar as perdas por efluentes.

A perda gasosa foi quantificada pela diferença entre a quantidade de MS da forragem no fechamento do silo e a quantidade de MS no balde na época da abertura.

As perdas totais de MS foram calculadas pela diferença entre a quantidade de MS da forragem ensilada no fechamento do silo e a quantidade de MS da silagem recuperada, descontando-se da quantidade de MS a perda por efluentes. De forma simplificada, pode-se equacionar a perda total de MS como a soma das perdas por gás e efluentes.

Cada amostra de silagem foi composta de duas a quatro porções retiradas da parte central da massa de forragem contida em cada silo. As amostras destinadas à determinação de pH, dos teores de etanol, CS em água, ácidos graxos voláteis e ácido lático foram colocadas em sacos plásticos e estocadas sob refrigeração $\left(5^{\circ} \mathrm{C}\right)$. As amostras utilizadas para as demais análises bromatológicas foram colocadas em sacos de papel e secas em estufa de ventilação forçada a $55^{\circ} \mathrm{C}$ por 72 horas.

As amostras secas de silagem foram moídas com peneira de malha de $1 \mathrm{~mm}$ e posteriormente analisadas para determinação da MS, em estufa a $105^{\circ} \mathrm{C}$ por 24 horas, matéria mineral, obtida pela incineração das amostras em mufla a $600^{\circ} \mathrm{C}$ por 3 horas, e dos teores de fibra em detergente neutro (FDN), conforme descrito por Silva \& Queiroz (2002). A digestibilidade in vitro da MS (DIVMS) foi analisada segundo Campos et al. (2001) e os teores de proteína bruta (PB) segundo AOAC (1990). Para o tratamento com uréia, o teor de PB foi determinado pelo método macro Kjeldahl (AOAC, 1990) em amostras úmidas de silagem que haviam sido mantidas congeladas $\left(-5^{\circ} \mathrm{C}\right)$.

Os teores de etanol, CS, ácidos graxos voláteis (AGV) e ácido lático foram determinados em extratos aquosos das amostras de silagem, obtidos segundo o método descrito por Kung Jr. (1996). Para isso, $25 \mathrm{~g}$ de amostra úmida foram processados com $225 \mathrm{~mL}$ de água destilada, em liquidificador, durante 1 minuto. Em seguida, o material foi filtrado em papel-filtro Whatman ${ }^{\circledR} 54$, acidificado com $\mathrm{H}_{2} \mathrm{SO}_{4}$ a $50 \%$ e centrifugado $(5000 \mathrm{~g}$ ) por 15 minutos e o extrato líquido armazenado em congelador $\left(-5^{\circ} \mathrm{C}\right)$ até o momento das análises. $\mathrm{O} \mathrm{pH}$ foi determinado nos extratos, antes da filtragem em potenciômetro digital, modelo DM $20^{\circledR}$ (Digimed Analítica, São Paulo). O teor de etanol foi obtido por leitura direta em auto-analisador bioquímico
YSI 2700 Select (Biochemistry Analyser, Yellow, Spring), contendo membrana enzimática específica para esse analito. Depois de calibrado com soluções padronizadas de etanol (2 g/L), o aparelho forneceu leitura direta em g/L.

As determinações dos teores de CS foram realizadas pelo método colorimétrico, segundo Dubois et al. (1956), diluindo os extratos aquosos das amostras de silagem na proporção de $1 \mathrm{~mL}$ de extrato para $20 \mathrm{~mL}$ de água destilada. Os teores de ácido lático foram determinados por cromatografia líquida de alta performance (HPLC) utilizando coluna de troca catiônica (Polyspher OA HY 51272; Merck, Amsterdam). A fase móvel consistiu de $\mathrm{H}_{2} \mathrm{SO}_{4}(0,004 \mathrm{~mol} / \mathrm{L})$, a uma taxa de $0,6 \mathrm{~mL} /$ minuto a $40^{\circ} \mathrm{C}$. Os ácidos graxos voláteis no extrato (acético e propiônico) foram determinados segundo metodologia descrita por Palmiquist \& Conrad (1971) em cromatógrafo líquidogasoso (Hewlett Packard ${ }^{\circledR} 5890$ series II) equipado com braço mecânico HP Integrator 3396 series II (Hewlett Packard company ${ }^{\circledR}$ ). O gás de arraste e os comburentes foram nitrogênio, hidrogênio e oxigênio, respectivamente, nas vazões de 20, 30 e $400 \mathrm{~mL} /$ minuto. As temperaturas do injetor, do detector e da coluna foram de 150, 190 e $115^{\circ} \mathrm{C}$, respectivamente.

O delineamento experimental utilizado foi o inteiramente casualizado, composto de quatro tratamentos e duas repetições. O modelo proposto foi analisado pelo PROC GLM do programa SAS (SAS, 1999) e as comparações realizadas pelo método dos mínimos quadrados (LSMEANS). As médias dos tratamentos foram comparadas com nível de significância de $5 \%$.

Com o objetivo de identificar as relações funcionais entre as variáveis, recorreu-se ao PROC CORR do programa SAS (SAS, 1999) para análise de correlação simples.

\section{Resultados e Discussão}

Os valores de MS obtidos neste estudo (Tabela 1) estão de acordo com a maioria dos reportados na literatura (Aroeira et al., 1993; Rodrigues \& Barbosa, 1999; Pereira et al., 2000; Azevedo et al., 2003; Fernandes et al., 2003). Na média, os teores de FDN encontrados foram próximos aos encontrados por Azevedo et al. (2003) e Fernandes et al. (2003), que avaliaram 15 variedades industriais com 16 meses (48,8 e 48,5\%). Os teores de PB da cana foram próximos aos encontrados por Coan et al. (2002), Molina et al. (2002), Pedroso et al. (2005) e Freitas et al. (2006), na média um pouco acima de $2 \%$ na MS, nos tratamentos sem adição de uréia. A concentração de PB da cana-de-açúcar após a adição de uréia atingiu os valores esperados próximos a $10 \%$ na MS. Os teores de CS foram próximos e superiores 
aos encontrados por Pedroso et al. (2005) e Bernardes et al. (2002), de 17,8 e 24\%, mas bem inferiores aos observados por Alli et al. (1983) e Campos et al. (2001) de 52 e 46,9\%, respectivamente. Os valores de DIVMS da cana-de-açúcar utilizada estiveram próximos aos limites estabelecidos por Rodrigues (2001), de 58 a 69\% em estudo com 18 variedades e de Campos et al (2001), de 60,9\%, porém inferiores aos obtidos por Freitas et al. (2006), de 77,5\% na MS.

Todas as silagens apresentaram, em relação ao material original, maiores valores de FDN e PB e redução nos teores de MS (Tabela 2). Do mesmo modo, esses resultados foram evidenciados por Pedroso et al. (2005) e Freitas et al. (2006). Em silagens, a fração fibrosa pode aumentar percentualmente na MS em condições de intensa formação de efluentes, uma vez que os componentes solúveis em água são perdidos proporcionalmente ao aumento na fração menos fermentável e insolúvel, particularmente os constituintes da parede celular (Van Soest, 1992) que ficam retidos na silagem. No caso da fermentação alcoólica, o consumo de $1 \mathrm{~mol}$ de glicose gera 2 moles de $\mathrm{H}_{2} \mathrm{O}$ e 2 moles de $\mathrm{CO}_{2}$ gerando intensas pedas de MS e acúmulo de água e componentes fibrosos (McDonald et al., 1991).

Especificamente neste estudo, a redução no teor de MS da silagem controle foi superior à maioria dos trabalhos, aproximadamente 32\%, diferentemente dos valores de 15 a $27 \%$ obtidos nos trabalhos de Pedroso et al. (2003) e Freitas et al. (2006), respectivamente.

O aumento na concentração de PB, em torno de 1 a 2 pontos percentuais, se deve as mesmas razões citadas anteriormente (Rotz \& Muck, 1994). No caso das silagens adicionadas de uréia, esse aumento foi em torno de 7 pontos percentuais.

Os valores de FDN encontrados nas silagens controle foram altos em relação à maioria dos trabalhos na literatura (Alli \& Baker, 1982; Coan et al., 2002), porém próximos aos obtidos por Pedroso et al. (2005) e Freitas et al. (2006), em torno de $65 \%$. O aumento de 32\% do teor de FDN nestas silagens confirma os valores encontrados por Coan et al. (2002). A redução nos teores de CS foi acompanhada de acúmulo de FDN, que, no caso da cana-de-açúcar sem aditivos, ficou em torno de $90 \%$. Essas perdas de CS nas silagens controle foram próximas às relatadas por Alli et al. (1982; 1983) e Freitas et al. (2006), de 93, 96 e 89\% e bem superiores aos valores obtidos por Pedroso et al. (2005), de $61 \%$.

A fermentação alcoólica foi dominante na silagem sem aditivo e na silagem aditivada com L. buchneri: os ácidos acético e lático foram detectados em segunda ordem nestas silagens (Tabela 3). A produção de etanol na silagem de cana-de-açúcar sem aditivos $(8,27 \%)$ foi bem inferior aos valores obtidos por Kung Jr. \& Stanley (1982) e Freitas et al. (2006) (17,8\% e 15,5\%), porém superiores aos encontrados por Preston et al. (1976), de 6,12\% em média. Valores mais próximos foram obtidos por Alli \& Baker (1982), Alli et al. (1983), Bernardes et al. (2002) e Pedroso et al. (2005), de 9, 7 e $7 \%$ na MS, respectivamente.

Na silagem controle e naquela com L. buchneri, o alto teor de etanol obtido foi superior ao encontrado nas silagens

Tabela 1 - Composição química da cana-de-açúcar e aditivos

\begin{tabular}{|c|c|c|c|c|c|c|}
\hline \multirow[t]{2}{*}{ Tratamento } & MS & DIVMS & Cinzas & $\mathrm{PB}$ & FDN & CS \\
\hline & \multicolumn{2}{|c|}{$(\%)$} & & \multicolumn{3}{|c|}{ (\% MS) } \\
\hline Controle & 31,1 & 63,6 & 1,66 & 2,83 & 48,7 & 21,7 \\
\hline Uréia & 31,8 & 64,8 & 1,67 & 9,59 & 48,3 & 25,5 \\
\hline L. buchneri & 30,6 & 65,2 & 1,61 & 3,09 & 47,9 & 27,0 \\
\hline L. buch $+P$. & 27,8 & 65,5 & 1,74 & 2,86 & 50,1 & 25,9 \\
\hline Média & 30,3 & 64,8 & 1,67 & 5,17 & 48,8 & 25,0 \\
\hline
\end{tabular}

L. buchneri = Lactobacillus buchneri; L.buch $+P .=$ Lactobacillus buchneri + Pediococcus pentosasseus; MS = matéria seca; DIVMS = digestibilidade in vitro da matéria seca; $\mathrm{PB}$ = proteína bruta; FDN = fibra em detergente neutro; $\mathrm{CS}$ = carboidratos solúveis.

Tabela 2 - Composição química das silagens de cana-de-açúcar

\begin{tabular}{lcccccc}
\hline Parâmetro & Controle & Uréia & L. buch & L. buch+P & Média & EPM \\
\hline MS & $22,5 \mathrm{C}$ & $24,2 \mathrm{~B}$ & $22,8 \mathrm{BC}$ & $26,9 \mathrm{~A}$ & 24,1 & 1,89 \\
Cinzas (\%MS) & $2,55 \mathrm{AB}$ & $2,30 \mathrm{~B}$ & $2,73 \mathrm{~A}$ & $2,36 \mathrm{~B}$ & 2,49 & 0,16 \\
PB (\%MS) & 3,51B & $16,33 \mathrm{~A}$ & $3,66 \mathrm{~B}$ & $2,95 \mathrm{~B}$ & 6,61 & 64,6 \\
FDN (\%MS) & $68,1 \mathrm{~A}$ & $63,6 \mathrm{AB}$ & $66,6 \mathrm{~A}$ & $60,3 \mathrm{~B}$ & 5,69 \\
CS (\%MS) & 2,51BC & $4,34 \mathrm{~B}$ & $2,38 \mathrm{C}$ & $11,03 \mathrm{~A}$ & 5,06 \\
\hline
\end{tabular}

L. buchneri = Lactobacillus buchneri; L.buch+P. = Lactobacillus buchneri + Pediococcus pentosasseus; MS = matéria Seca; PB = proteína bruta; FDN = fibra em detergente neutro; $C S=$ carboidratos solúveis; $E P M=$ erro-padrão da média. Letras diferentes na mesma linha indicam diferença significativa $(P<0,05)$. 
Tabela 3 - Parâmetros fermentativos e contagem de bactérias láticas e leveduras em silagens de cana-de-açúcar tratadas com aditivos químicos e microbianos

\begin{tabular}{|c|c|c|c|c|c|c|}
\hline Parâmetro & Controle & Uréia & L. buch & L. buch $+\mathrm{P}$ & Média & EPM \\
\hline $\mathrm{pH}$ & $2,94 \mathrm{~B}$ & 3,52A & $2,85 \mathrm{BC}$ & $2,73 \mathrm{C}$ & 3,01 & 0,14 \\
\hline Álcool (\% MS) & $8,27 \mathrm{~B}$ & $2,75 \mathrm{C}$ & $11,53 \mathrm{~A}$ & $1,30 \mathrm{D}$ & 5,96 & 2,74 \\
\hline Ácido lático (\% MS) & $1,17 \mathrm{~B}$ & $3,50 \mathrm{~A}$ & $1,80 \mathrm{~B}$ & $2,83 \mathrm{~A}$ & 2,33 & 0,78 \\
\hline Ácido lático (mmol/L) & $39,5 B$ & $118,1 \mathrm{~A}$ & $60,8 \mathrm{~B}$ & $95,3 \mathrm{~A}$ & 78,4 & 26,4 \\
\hline Ácido acético (\% MS) & $5,55 \mathrm{C}$ & $6,97 \mathrm{~B}$ & $6,12 \mathrm{C}$ & $9,26 \mathrm{~A}$ & 6,96 & 0,73 \\
\hline Ácido acético (mmol/L) & $280,6 \mathrm{C}$ & $352,4 \mathrm{~B}$ & $309,3 \mathrm{C}$ & $468,0 \mathrm{~A}$ & 352,6 & 36,8 \\
\hline Ácido propiônico (\% MS) & 0,23 & 0,14 & 0,24 & 0,24 & 0,21 & 0,11 \\
\hline Ácido propiônico (mmol/L) & 8,72 & 5,57 & 9,42 & 9,28 & 8,25 & 4,17 \\
\hline LAB (Log ufc/g) & 2,05 & 2,72 & 2,09 & 2,16 & 2,25 & 0,45 \\
\hline LEV (Log ufc/g) & $5,85 \mathrm{~B}$ & $6,85 \mathrm{AB}$ & $6,53 B$ & $7,69 \mathrm{~A}$ & 6,73 & 0,54 \\
\hline
\end{tabular}

L. buchneri = Lactobacillus buchneri; L.buch+P. = Lactobacillus buchneri + Pediococcus pentosasseus; LAB = bactérias láticas; LEV = Leveduras; EPM = erro-padrão da média. Letras diferentes na mesma linha indicam diferença significativa $(P<0,05)$.

com uréia e com a combinação de bactérias L. buchneri e Pediococcus $(\mathrm{P}<0,05)$ e foi ocasionado pelo maior consumo de CS, perdas de MS e conseqüente aumento na fração de FDN $(\mathrm{P}<0,05)$. Ao controlar a fermentação alcoólica pela adição da uréia e, com a combinação de bactérias, a menor perda de MS $(\mathrm{P}<0,05)$ os teores de MS próximos à faixa de 25 a 35\%, considerada ideal na obtenção de silagens de boa qualidade (Cheeke, 1999), o que corrobora as afirmações de Pedroso (2003) sobre o controle da controle da fermentação alcoólica.

Esperava-se que as silagens de cana-de-açúcar com L. buchneri associada ou não a bactérias homoláticas levasse a reduções significativas na produção de etanol pela inibição no desenvolvimento das leveduras. As bactérias heteroláticas têm a capacidade de converter parte do ácido lático formado durante as primeiras fermentações em ácido acético e 1,2-propanodiol sob condições de anaerobiose (Oude Elferink et al., 2001). Sabe-se que a quantidade de ácido acético não dissociado é o fator mais importante a ser considerado nos mecanismos de inibição do crescimento de leveduras (Moon, 1983; Weissbach, 1996), normalmente são controladas com teores de ácido acético acima de 5,6 g/L no meio de cultura ( $94 \mathrm{mmol} / \mathrm{L}$ ), ou seja, $2 \%$ de ácido acético na MS em silagens com 25\% de MS (Woolford, 1975).

Neste experimento, as concentrações de ácido acético das silagens (5,6 a 9,3\% da MS) foram superiores aos valores observados em silagens de cana-de-açúcar por Freitas et al. (2006), de 2,6 a 4,5\%, e por Andrade et al. (2001), que, em todas as silagens, obtiveram variação de 0,9 a 2,2\%. Os valores de ácido acético das silagens foram, do mesmo modo, superiores aos observados por Ranjit \& Kung Jr. (2000), de 3,6\%, e próximos aos encontrados por Nishiro et al. (2003), de 6,33\%, utilizando silagens de milho adicionadas de L. buchneri na grandeza de Log de $10^{6}$ ufc/g MS.
Os maiores valores de ácido acético foram obtidos com a adição da combinação de bactérias $L$. buchneri e Pediococcus, seguido pela silagem adicionada com uréia. Não houve diferenças significativas entre silagem com L. buchneri e controle. Uma possível explicação para a falta de efetividade da adição de $L$. buchneri é a quantidade utilizada de bactérias (3,64 × 10 $\mathrm{ufc} / \mathrm{g} \mathrm{MV})$, possivelmente insuficiente para promover mudanças na fermentação e diminuir significativamente a produção de etanol. Ressalta-se que vários trabalhos têm comprovado reduções sobre a população de leveduras apenas com uso de L. buchneri em torno de $10^{6}$ ufc/g MV (Driehuis et al., 1999; Ranjit \& Kung Jr., 2000).

Outra explicação para a ausência de efeito de $L$. buchneri nas silagens de cana-de-açúcar seria a inviabilidade das bactérias utilizadas. Talvez um modo de verificar esta hipótese seja pela quantidade de 1,2-propanodiol comparada à silagem não aditivada. Oude Elferink et al. (2001) mostraram que 1,2-propanodiol é produzido junto com o ácido acético durante a degradação anaeróbia do ácido lático pela ação de $L$. buchneri e pode se acumular na massa ensilada ocasionando diferenças na fermentação em relação às silagens não aditivadas. No entanto, em algumas silagens a presença de bactérias que degradam o 1,2-propanodiol a 1-propanol e a ácido propiônico como o L. diolivorans (Krooneman et al., 2002) pode dificultar essas observações. Em alguns casos, não foram observados aumentos no 1,2-propanodiol, apesar da ação do $L$. buchneri em silagens de milho (Weinberg et al., 1999). Neste estudo não foram determinadas as concentrações de 1,2-propanodiol, portanto, não foi possível a confirmação dessas considerações.

De modo contrário à ação de bactérias heteroláticas, inoculantes bacterianos contendo bactérias homoláticas são eficientes na produção de ácido lático, pois aumentam 
a velocidade de acidificação das silagens, reduzindo o $\mathrm{pH}$ final e a degradação protéica na silagem (Weinberg \& Muck, 1996; Driehuis et al., 1999). O principal objetivo no uso dessas bactérias homoláticas foi reduzir o risco de fermentações por bactérias do gênero Clostridium e aumentar o valor nutricional do volumoso. Entretanto, resultados de vários estudos indicam que bactérias homofermen-tativas diminuem a estabilidade aeróbica por não controlarem leveduras e preservarem CS (Bolsen et al., 1992; Ranjit \& Kung Jr., 2000). No caso da cana, com predominância de fermentação alcoólica realizada por leveduras, o uso de bactérias homoláticas isoladas não foi promissor, pois houve aumento do teor de etanol nas silagens aditivadas (Pedroso et al., 2005).

Entretanto, em recente estudo realizado por Adesogan \& Salawu (2004), o uso da combinação de bactérias homo e heteroláticas tem sido eficiente em aumentar a velocidade de acidificação da massa ensilada e em reduzir o pH final, além do controle do crescimento de leveduras decorrente da maior produção de ácido acético. Driehuis et al. (2001), em três ensaios com silagens de gramíneas e o uso combinado de bactérias homo e heteroláticas, verificaram em um deles, grande aumento na preservação dos CS. Neste ensaio, foram obtidos nas silagens com combinação de bactérias teores semelhantes de ácido lático em comparação às silagens inoculadas apenas com bactérias homoláticas (98,8 g/kg MS), no entanto, os teores de ácido acético foram mais altos com a combinação de bactérias $(22,3 \times 9,3 \mathrm{~g} / \mathrm{kg}$ MS). Isso ocasionou aumentos na acidificação e redução no $\mathrm{pH}$ final, restringindo as perdas de CS e, possivelmente, maior estabilidade no período pós-abertura.

Nos outros dois ensaios realizados por Driehuis et al. (2001), as silagens aditivadas com a combinação de bactérias apresentaram aumento nos teores de ácido acético em relação a silagem aditivada apenas com bactérias homoláticas (60, 7 × 18,8 g/kg MS), no entanto, esse aumento não foi acompanhado de altos valores de ácido lático. Segundo Driehuis et al. (2001), o sucesso do uso de combinações de bactérias ocorre somente se houver alta atividade de ambas as bactérias, homo e heteroláticas. Portanto, parece haver um sinergismo entre os ácidos acético e lático, e o aumento simultâneo de ambos permite maior controle da fermentação alcoólica (crescimento das leveduras) e não apenas o aumento expressivo de um deles, como ocorreu neste estudo.

Neste ensaio as silagens inoculadas com a combinação das bactérias $L$. buchneri e Pediococcus apresentaram maior eficiência em restringir este tipo de fermentação, o que resultou em aumento no teor de ácido acético em relação às demais silagens, reduzindo significativamente as perdas de MS e CS $(\mathrm{P}<0,05)$. Neste caso, a maior concentração de $L$. buchneri utilizada $\left(1 \times 10^{6} \mathrm{ufc} / \mathrm{g}\right)$ pode ter sido uma das causas da diferença nos teores de ácido acético em relação à silagem aditivada apenas com bactérias heteroláticas (Driehuis et al., 1999; Ranjit \& Kung Jr., 2000).

$\mathrm{O}$ pH das silagens não aditivadas atingiu valores bem inferiores aos encontrados na literatura, próximos de 3,5 (Alli \& Baker, 1982; Kung Jr. \& Stanley, 1982; Coan et al., 2002; Pedroso et al., 2005; Freitas et al., 2006). A adição de uréia fez com que estas silagens apresentassem, pelo seu efeito tamponante, $\mathrm{pH}$ mais elevado $(\mathrm{P}<0,05)$. Esses resultados podem, em parte, explicar os efeitos benéficos do nitrogênio no controle da produção de etanol na redução das perdas de CS e MS e na melhora da digestibilidade in vitro da $\mathrm{MS}(\mathrm{P}<0,05)$ em relação às silagens controle.

Uma das especulações acerca da ação dos aditivos nitrogenados em silagens de cana-de-açúcar é que a elevação do $\mathrm{pH}$ nos primeiros estágios fermantativos favoreceria o desenvolvimento de bactérias lácticas. No caso destas silagens, como o $\mathrm{pH}$ reduz rapidamente a valores menores que 3, favorece o desenvolvimento de leveduras que sobrevivem em $\mathrm{pH}$ próximos a 2 (McDonald et al., 1991). Esse maior tamponamento nas silagens pela uréia, aliado a um substrato com maior nível protéico, pode ter contribuído para um ambiente mais favorável para desenvolvimento das bactérias láticas. Nas silagens aditivadas com uréia, a maior concentração de ácido lático $(\mathrm{P}<0,05)$ em relação às silagens sem aditivos corrobora a teoria proposta (Keady \& O‘Kiely, 1998).

As concentrações de ácido lático das silagens sem aditivos $(1,17 \%$ na MS) e com L buchneri $(1,80 \%)$ foram inferiores às observadas por Andrade et al. (2001) e Freitas et al. (2006), de 4,3\%, e por Kung Jr. \& Stanley (1982), de 2,82 e 5,62\% nas silagens produzidas com cana-de-açúcar com 6 e 24 meses de idade. Esses baixos valores podem ser atribuídos à fermentação predominantemente alcoólica. No caso das silagens aditivadas com a combinação de bactérias homo e heteroláticas, apesar dos valores superiores ao da silagem controle, foram de baixa magnitude, talvez em virtude da alta interconversão do ácido lático a ácido acético (Driehuis et al., 2001).

Todos os valores de ácido lático das silagens (40 a $120 \mathrm{mmol} / \mathrm{L}$ ) foram inferiores aos determinados por Moon (1983), em torno de $400 \mathrm{mmol} / \mathrm{L}$, que inibiu 50\% do crescimento de quatro espécies de leveduras estudadas.

As concentrações de ácido propiônico estão na faixa de 0 a $1 \%$ e não diferiram entre as silagens, que podem ser classificadas como de boa qualidade, como citado por Mahanna (1993). No entanto, foram inferiores aos valores observados por Freitas et al. (2006). O propionato é um dos ácidos de cadeia curta de maior efeito antimicrobiano, pois 
reduz o crescimento de leveduras em pequenas concentrações. Essa característica pode ser atribuída à ação no citoplasma, pela redução do pH celular, como impedindo o transporte de aminoácidos entre a membrana celular (Freese et al., 1973). Segundo Moon (1983), em pesquisa com quatro espécies de leveduras, a inibição do crescimento pelo propionato ocorre a partir de $6 \mathrm{mmol} / \mathrm{L}$, o que foi observado nas silagens controle e com a adição dos inoculantes bacterianos. Entretanto, como relatado por esse autor, somente em concentrações entre 10 a $20 \mathrm{mmol} / \mathrm{L}$ houve $50 \%$ de redução no crescimento nas duas especies de leveduras. Com as espécies Hansenula canadensis e Endomycopsis burtonii, essa redução foi obtida apenas em concentrações de $30 \mathrm{mmol} / \mathrm{L}$. No caso das silagens deste experimento (5 a $10 \mathrm{mmol} / \mathrm{L}$ ) os teores de ácido propiônico foram baixos e inadequados para influenciar a inibição do crescimento das leveduras.

As menores populações de leveduras foram obtidas nas silagens sem aditivos e nas silagens aditivadas com L. buchneri $(\mathrm{P}<0,05)$. Não houve relação entre a população de leveduras, a produção de etanol e o teor de ácido acético nas silagens deste estudo, pois as maiores contagens foram obtidas nas silagens com maiores teores de ácido acético e menores teores de etanol. Essa falta de correlação também foi evidenciada por Freitas et al. (2006), que relataram que o controle da síntese de etanol esteve mais relacionado ao controle da MS da silagem que aos teores de ácido acético. Neste caso, a ensilagem de cana-de-açúcar e L. buchneri mais resíduo de soja aumentou o teor de MS da silagem (28,2\% vs $20,7 \%$ na silagem com L. buchneri apenas), levando ao controle da produção de etanol (8,4\% vs 19,3\% na MS).

No caso das silagens produzidas com uréia, o controle da população de leveduras poderia ocorrer como resultado da ação antifúngica do nitrogênio (Britt \& Huber, 1975), o que também não foi verificado nas silagens deste experimento. As menores contagens de leveduras $(\mathrm{P}<0,05)$ foram obtidas apenas nas silagens controle e naquelas com L. buchneri, apesar da alta concentração de etanol, o que indica talvez maior controle, não por ácido acético, mas pelo próprio etanol (Driehuis \& Wikselaar, 2000).

Apesar de não promoverem a diminuição na população de leveduras, a combinação de bactérias homo e heteroláticas foi eficiente em diminuir a atividade das leveduras, pois promoveu redução nas perdas de gases e maior recuperação de MS $(\mathrm{P}<0,05)$ (Tabela 4).

As perdas de gases na silagem de cana-de-açúcar controle (31,2\%) foi semelhante aos dados obtidos por Kung Jr. \& Stanley (1982) e Freitas et al. (2006), com média de 30\%, mas superior ao obtido por Pedroso et al. (2005), de 6,14\%.
Neste estudo, a combinação de bactérias reduziu as perdas de gases em aproximadamente $50 \%$, de 30,1 para $16,5 \%$.

A produção de silagens de cana-de-açúcar com Lactobacillus buchneri, por não controlar a produção de etanol, não foi eficiente em diminuir as perdas de MS $(\mathrm{P}<0,05)$. Essas observações contrariam os relatos de Pedroso et al. (2005), que constataram redução nas perdas gasosas (de 9,7\% para 8,4\% na MS) e melhora significativa na recuperação de MS (de 80,9\% para 90,5\%) nas silagens de cana-de-açúcar aditivadas. De modo semelhante, Siqueira (2005) obteve maior recuperação de MS da silagem de canade-açúcar aditivada com Lactobacillus buchneri em comparação à silagem controle (80,8 vs $67,5 \%)$.

Existem poucos dados sobre perda de efluentes em silagens de cana. Os dados obtidos foram maiores que os evidenciados por Pedroso et al. (2003), de 15,1 kg/t de MV na silagem sem aditivo, o que está relacionado à perda de MS e à produção de água metabólica, que reduzem o nível de MS da silagem em até $22 \%$, como verificado nas silagens controle deste estudo (McDonald et al., 1991).

Houve maior perda de digestibilidade in vitro nas silagens controle e com L. buchneri (30\%) em relação à silagens com uréia e com a combinacao de bactérias homo e heteroláticas (23\%) (Tabelas 1 e 4). A uréia e a combinação L. buchneri e Pediococcus, por controlarem melhor a fermentação alcoólica e as perdas de CS, proporcionaram silagens de maior digestibilidade $(\mathrm{P}<0,05)$, similares aos valores obtidos por Freitas et al. (2006), de 58\% e superiores aos obtidos por Pedroso (2003), de 48\%. Esses valores são considerados bons e se comparam aos registrados por Rodrigues et al. (2002), de 60,8\% em silagens de sorgo. Verifica-se dessa forma que o controle da produção de etanol promove ganhos quantitativos, em virtude da menor perda de gases e da maior recuperação de MS, juntamente com ganhos qualitativos proporcionados pelo aumento da digestibilidade in vitro.

A relação FDN/CS da cana-de-açúcar tem influência marcante sobre a digestibilidade, o consumo e o desempenho animal. Essa característica tem variado entre as variedades comerciais, a idade, a época de corte e os tratos culturais, o que pode justificar discrepâncias marcantes entre as pesquisas.

\section{Conclusões}

O aditivo uréia e a combinação de bactérias homo e heteroláticas (L. buchneri e Pediococcus) apresentaram características desejáveis para a ensilagem de cana-deaçúcar, pois resultaram em maiores teores dos ácidos orgânicos, inibição na síntese etanol e maior recuperação de CS 
Tabela 4 - Perdas por gases e efluentes, recuperação de matéria seca e digestibilidade in vitro de silagens de cana-de-açúcar tratadas com aditivos químico ou microbianos

\begin{tabular}{|c|c|c|c|c|c|c|}
\hline Parâmetro & Controle & Uréia & L. buch & L. buch $+\mathrm{P}$. & Média & EPM \\
\hline Gases (\% da MS) & $31,2 \mathrm{~A}$ & $25,9 \mathrm{~A}$ & $30,1 \mathrm{~A}$ & $16,5 \mathrm{~B}$ & 25,9 & 5,97 \\
\hline Efluentes (kg/t MV) & 39,2 & 45,4 & 46,1 & 44,4 & 43,8 & 4,31 \\
\hline Recuperação MS (\%) & $66,0 \mathrm{~B}$ & $70,6 \mathrm{~B}$ & $66,6 \mathrm{~B}$ & $79,7 \mathrm{~A}$ & 70,7 & 6,13 \\
\hline DVMS (\%) & $50,4 \mathrm{~B}$ & $56,8 \mathrm{~A}$ & $50,6 \mathrm{~B}$ & $57,8 \mathrm{~A}$ & 53,9 & 3,39 \\
\hline
\end{tabular}

L. buchneri = Lactobacillus buchneri; L. buch+P. = Lactobacillus buchneri + Pediococcus pentosasseus; DIVMS = digestibilidade verdadeira in vitro da matéria seca; $M V=$ matéria verde; $E P M=$ erro-padrão da média. Letras diferentes na mesma linha indicam diferença significativa (P<0,05).

e da digestibilidade final (contrariam o resumo). O aditivo L. buchneri $5 \times 10^{4} \mathrm{ufc} / \mathrm{g}$, quando adicionado isoladamente, não apresentou boa eficácia às características de fermentação. As respostas discrepantes ao uso desse microrganismo sugerem a reavaliação das dosagens recomendadas para silagem de cana-de-açúcar.

\section{Literatura Citada}

ADESOGAN, A.T.; SALAWU, M.B. Effect of applying formic acid, heterolactic bacteria or homolactic and heterolactic bacteria on the fermentation of bi-crops of peas and wheat. Journal of the Science Food and Agriculture, v.84, n.9, p.983-992, 2004.

ALLI, I.; BAKER, B.E.; GARCIA, G. Studies on the fermentation of chopped sugarcane. Animal Feed Science and Technology, v.7, p.411-417, 1982.

ALLI, I.; FAIRBAIRN, R.; BAKER, B.E. et al. The effects of ammonia on the fermentation of chopped sugarcane. Animal Feed Science and Technology, v.9, p.291-299, 1983.

ALVAREZ, F.J.; PRESTON, T.R. Ammonia/molasses and urea/ molasses as additives for ensiled sugarcane. Tropical Animal Production, v.1, p.98-104, 1976.

ANDRADE, J.B.; FERRARI JR., E.; BRAUN, G. Valor nutritivo da silagem de cana-de-açúcar tratada com uréia e acrescida de rolão de milho. Pesquisa Agropecuária Brasileira, v.36, n.9, p.1169-1174, 2001.

AROEIRA, L.J.M.; SILVEIRA, M.I.; LIZIEIRE, R.S. Degrababilidade no rúmen e taxa de passagem da cana-deaçúcar mais uréia, do farelo de algodão e do farelo de arroz em novilhos mestiços europeu x zebu. Revista Brasileira de Zootecnia, v.22, n.4, p.52-564, 1993.

ASSOCIATION OF OFFICIAL ANALYTICAL CHEMISTS - AOAC. Official methods of analysis. 15.ed. Arlington: AOAC: 1990. v.1, 1117p.

AZEVÊDO, J.A.G.; PEREIRA, J.C.; CARNEIRO, P.C.S. et al. Avaliação da divergência nutricional de variedades de canadeaçúcar (Saccharum spp.). Revista Brasileira de Zootecnia, v.32, n.6, p.1431-1442, 2003.

BERNARDES, T.F.; SILVEIRA, R.N.; COAN, R.M. et al. Características fermentativas e presença de levedura na canadeaçúcar crua ou queimada ensilada com aditivo. In: REUNIÃO ANUAL DA SOCIEDADE BRASILEIRA DE ZOOTECNIA, 39., 2002, Recife. Anais... Recife: Sociedade Brasileira de Zootecnia, 2002. (CD-ROM).

BOLSEN, K.K.; LIN, C.; BRENT, B.E. et al. Effect of silage additives on the microbial succession and fermentation process of alfalfa and corn silage. Journal of Dairy Science, v.75, n.11, p.381-389, 1992.

BRITT, D.G.; HUBER, J.T. Fungal growth during fermentation and refermentation of nonprotein nitrogen treated corn silage. Journal of Dairy Science, v.58, n.11, p.1667-1671, 1975.
BRITT, D.G.; HUBER, J.T.; ROGERS, A.L. Fungal growth and acid production during fermentation and refermentation of organic acid treated corn silages. Journal of Dairy Science, v.58, p.532-539, 1975.

CAMPOS, F.P.; SAMPAIO, A.A.M.; VIEIRA, P.F. et al. Digestibilidade in vitro/gás de volumosos exclusivos ou combinados avaliados pelo resíduo remanescente da digestão da matéria seca e produção de gás. Revista Brasileira de Zootecnia, v.30, n.5, p.15791589, 2001.

CHEEKE, P.R. Applied animal nutrition: feeds and feeding. 2.ed. New Jersey: Prentice-Hall, 1999. 525p.

COAN, R.M.; SILVEIRA, R.N.; BERNARDES, T.F. et al. Composição química da cana-de-açúcar crua ou queimada ensilada com aditivo. In: REUNIÃO ANUAL DA SOCIEDADE BRASILEIRA DE ZOOTECNIA, 39., 2002, Recife. Anais.. Recife: Sociedade Brasileira de Zootecnia, 2002. (CD-ROM).

DRIEHUIS, F.; OUDE ELFERINK, S.J.W.H.; SPOELSTRA, S.F. Anaerobic lactic acid degradation during ensilage of whole crop maize inoculated with Lactobacillus buchneri inhibits yeast growth and improves aerobic stability. Journal of Applied Microbiology, v.87, p.583-594, 1999.

DRIEHUIS, F.; OUDE ELFERINK, S.J.W.H.; Van WIKSELAAR, P.G. Fermentation characteristics and aerobic stability of grass silage inoculated with Lactobacillus buchneri with or without homofermentative lactic acid bacteria. Grass and Forage Science, v.56, p.330-343, 2001.

DRIEHUIS, F.; Van WIKSELAAR, P.G. The occurrence and prevention of ethanol fermentation in high-dry-matter grass silage. Journal of Science of Food and Agriculture, v.80, p.711-718, 2000.

DUBOIS, M.; GILLES, K.A.; HAMILTON, J.K. et al. Colorimetric method for determination of sugars and related substances. Analytical Chemistry, v.28, p.350, 1956.

FERNANDES, A.M.; QUEIROZ, A.C.; PEREIRA, J.C. et al. Composição químico-bromatológica de variedades de canadeaçúcar (Saccharum spp L.) com diferentes ciclos de produção (Precoce e Intermediário) em três idades de corte. Revista Brasileira de Zootecnia, v.32, n.4, p.977-985, 2003.

FREESE, E.; SHEW, C.; GALLIERS, E. Function of lipophilic acids as antimicrobial food additives. Nature, v.24, p.321-325, 1973.

FREITAS, A.W.P.F.; PEREIRA, J.C.; ROCHA, F.C. et al. Avaliação da qualidade nutricional da silagem de cana-de-açúcar com aditivos microbianos e enriquecida com resíduos da colheita da soja Revista Brasileira de Zootecnia, v.35, n.1, p.38-47, 2006.

KEADY, T.W.J.; O'KIELY, P. An evaluation of potassium and nitrogen fertilization and date of harvest on fermentation, effluent production, dry matter recovery and predicted feeding value of silage. Grass and Forage Science, v.53, p326-337, 1998.

KROONEMAN, J.; FABER, F.; ALDERKAMP, A. Lactobacillus diolivorans sp. nov., a 1,2-propanediol degrading bacterium isolated from aerobically stable maize silage. International Journal of Systematic and Evolutionary Microbiology, v.52, p.639-646, 2002.

KUNG JR., L. Microbial and chemical additives for silage - effects on fermentation and animal response. In: WORKSHOP SOBRE 
MILHO PARA SILAGEM, 2000, Piracicaba. Anais... Piracicaba: Fundação de Estudos Agrários Luiz de Queiroz, 2000. v.2, p.53.

KUNG JR., L. Preparation of silage water extracts for chemical analyses. Standard operating procedure - 001 2.03.96. ed. Delaware: University of Delaware - Ruminant Nutrition Lab., 1996. 32p.

KUNG JR., L.; RANJIT, N.K. The effect of Lactobacillus buchneri and other additives on the fermentation and aerobic stability of barley silage. Journal of Dairy Science, v.84, p.1149-1155, 2001.

KUNG JR., L.; STANLEY, R.W. Effect of stage of maturity on the nutritive value of whole-plant sugarcane preserved as silage. Journal of Animal Science, v.54, p.689-696, 1982.

MAHANNA, B. Troubleshooting silage problems. In: STATE APPLIED NUTRITION CONFERENCE, 4., 1993, Wisconsin. Proceedings... Wisconsin: 1993. p.1-21.

McDONALD, P.; HENDERSON, A.R.; HERON, S.J.E. The biochemistry of silage. 2.ed. Marlow: Chalcomb Publication, 1991. 340p.

MOLINA, L.R.; FERREIRA, D.A.; GOLÇALVES, L.C. et al. Padrão de fermentação da silagem de cana-de-açúcar (Saccharum officinarum L.) submetida a diferentes tratamentos. In: REUNIÃO ANUAL DA SOCIEDADE BRASILEIRA DE ZOOTECNIA, 39., 2002, Recife. Anais... Sociedade Brasileira de Zootecnia, 2002. (CD-ROM).

MOON, N.J. Inhibition of the growth of acid tolerant yeasts by acetate, lactate and propionate and their synergistic mixtures. Journal of Applied Bacteriology, v.55, p.453-460, 1983.

OUDE ELFERINK, S.J.W.H.; KROONEMAN, J.; GOTTSCHAL, J.C. et al. Anaerobic conversion of lactic acid to acetic acid and 1,2 propanediol by Lactobacillus buchneri. Applied Environmental Microbiology, v.67, p.125-132, 2001.

PALMIQUIST, D.; CONRAD, H. Origin of plasma fatty acids in lactating cows fed high fat diets. Journal of Dairy Science, v.74, p.3152-3158, 1971.

PEDROSO, A.F. Aditivos químicos e microbianos como inibidores da produção de etanol em silagens de cana de açúcar (Saccharum officinarum L.). Piracicaba: Escola Superior de Agricultura "Luiz de Queiroz", 2003. 120p. Tese (Doutorado em agronomia) - Escola Superior de Agricultura "Luiz de Queiroz”, 2003.

PEDROSO, A.F.; NUSSIO, L.G.; PAZIANI, S.F. et al. Dinâmica da fermentação e da microflora epífita em silagem de cana-deaçúcar. Scientia Agrícola, v.62, n.5, p.427-432, 2005.

PEREIRA, E.S.; QUEIROZ, A.C.; PAULINO, M.F. et al. Determinação das frações protéicas e de carboidratos e taxas de degradação in vitro da cana-de-açúcar, da cama de frango e do farelo de algodão. Revista Brasileira de Zootecnia, v.29, n.6, p.1887-1893, 2000.

PRESTON, T.R.; HINOJOSA, C.; MARTINEZ, L. Ensiling of sugar cane with ammonia molasses and mineral acids. Tropical Animal Production, v.1, p.120-126, 1976.
RANJIT, N.K.; KUNG JR., L. The effect of Lactobacillus buchneri, Lactobacillus plantarum, or a chemical preservative on the fermentation and aerobic stability of corn silage. Journal of Dairy Science, v.83, p.526-535, 2000

RODRIGUES, A.A.; BARBOSA, P.F. Efeito do teor protéico do concentrado no consumo da cana-de-açúcar com uréia e ganho de peso de novilhas em crescimento. Revista Brasileira de Zootecnia, v.28, n.2, p.421-424, 1999.

RODRIGUES, A.A.; CRUZ, G.M.C.; BATISTA, L.A.R. et al. Qualidade de dezoito variedades de cana-de-açúcar como alimento para bovinos. In: REUNIÃO DA SOCIEDADE BRASILEIRA DE ZOOTECNIA, 38., 2001, Piracicaba. Anais. Piracicaba: Sociedade Brasileira de Zootecnia, 2001. p.1111-1112.

RODRIGUES, P.H.M.; SENATORE, A.L.; ANDRADE, S.J.T. et al. Efeitos da adição de inoculantes microbianos sobre a composição bromatológica e perfil fermentativo da silagem de sorgo produzida em silos experimentais. Revista Brasileira de Zootecnia, v.31, n.6, p.2373-2379, 2002.

ROTZ, C.A.; MUCK, E.M. Changes in forage quality during harvest and storage. In: FAREY JR., G.C. (Ed.) Forage quality, evaluation, and utilization. Madison: American Society of Agronomy, 1994. p.828-868.

STATISTICAL ANALYSIS SYSTEM - SAS. SAS users' guide: statistics. Cary: SAS Institute, 1999, 965p.

SILVA, D.J.; QUEIROZ, A.C. Análise de alimentos: métodos químicos e biológicos. Viçosa, MG: Universidade Federal de Viçosa, 2002. 165p.

SIQUEIRA, G.R. Cana-de-açúcar (Saccharum officinarum L.) ensilada com aditivos químicos e microbianos. Jaboticabal: Universidade Estadual Paulista, 2005. 92p. Dissertação (Mestrado em Zootecnia) - Universidade Estadual Paulista, 2005.

Van SOEST, P.J. Nutritional ecology of the ruminant. 2.ed. New York: Cornell University Press, 1994. 476p.

WOOLFORD, M.K. Microbial screening of food preservatives, cold sterilants and specific antimicrobial agents as potential silage additives. Journal of Science of Food and Agriculture, v.26, p.229-237, 1975.

WEINBERG, Z.G.; MUCK, R.E. New trends and opportunities in the development and use ofoculants for silage. FEMS Microbiology Reviews, v.19, p.53-68, 1996.

WEINBERG, Z.G.; SZAKACS, G.; ASHBELL, G. et al. The effect of Lactobacillus buchneri and L. plantarum, applied at ensiling, on the ensiling fermentation and aerobic stability of wheat and sorghum silages. Journal of Industrial Microbiology and Biotechnology, v.23, n.3, p.218-222, 1999.

WEISSBACH, F. New developments in crop conservation. In: INTERNATIONAL SILAGE CONFERENCE, 11., 1996, Aberystwyth. Proceedings... Aberystwyth: Institute of Grassland and Environmental Research, 1996. p.11-25. 